\title{
El viaje del H.M.S. Beagle
}

\author{
Eugenia M. del Pino
}

Escuela de Ciencias Biológicas de la Pontificia Universidad Católica del Ecuador. edelpino@puce.edu.ec

En las grandes travesías de exploración en la época en la que se realizó el viaje del H.M.S. Beagle (Figura 1), un artista acompañaba a la expedición para documentar el viaje, pues no existían cámaras fotográficas y todas las ilustraciones de la naturaleza se basaban en minuciosos dibujos.

Debido a la importancia de ilustrar la expedición, el Capitán Robert FitzRoy, contrató con fondos de su propio patrimonio a un artista como ilustrador oficial de la expedición. La persona escogida fue un paisajista de gran trayectoria, el artista británico Augustus Earle (1793-1838), quien tenía gran experiencia en viajes de exploración. Éste, quien se encontraba entre los miembros de más edad, se enfermó y por tal motivo se separó de la expedición en 1832 en la ciudad de Montevideo y regresó a Inglaterra. A la sazón, Conrad Martens (18011878), un joven pintor británico, se encontraba en Río de Janeiro con rumbo a la India. $\mathrm{Al}$ enterarse de la vacante en el H. M.S. Beagle viajó a Montevideo en julio de 1833 y fue inmediatamente contratado por el Capitán FitzRoy como artista oficial. Para facilitar las exploraciones, el Capitán FitzRoy adquirió una nave adicional, el H.M.S. Adventure y en ella zarpó de Montevideo en diciembre de 1833 y navegó por las costas de Patagonia, Tierra del Fuego y las Islas Malvinas. Siguió por el Estrecho de Magallanes y llegó al Océano Pacífico. En 1834, exploró la Isla de Chiloé y las costas de Chile hasta Valparaíso. Justamente en Valparaíso, el Almirantazgo Británico rehusó cubrir los costos de la compra y operación del H. M.S. Adventure, por cuyo motivo el Capitán FitzRoy se vio forzado a vender dicha nave. El resultado fue que en la nave principal, el H.M.S. Beagle, no hubo espacio para alojar al artista y Conrad Martens fue despedido.

Después de viajar por Chile y Perú, Conrad Martens se dirigió a Sidney Australia, donde fijó su residencia, dedicándose a pintar la naturaleza, reproducir imágenes de su viaje en el H.M.S. Beagle y a dictar clases de pintura. Conrad Martens fue un dotado artista y sus acuarelas y dibujos muestran la naturaleza de América del Sur que visitó Darwin, reflejando en parte la vida cotidiana. Sus imágenes son la documentación más rica del viaje del H.M.S. Beagle. Desgraciadamente, esta documentación es parcial ya que Conrad Martens no visitó la parte norte de la costa sudamericana del Pacífico y por tanto no hay ilustraciones suyas de las Islas Galápagos. Las acuarelas y pinturas de Conrad Martens permanecieron en colecciones particulares y fueron prácticamente desconocidas hasta el año de 1960 cuando un bisnieto de Charles Darwin, Richard Darwin Keynes, se dedicó a investigar al respecto y a documentar este rico acervo visual (Keynes, 1979). Algunas imágenes del trabajo de Conrad Martens se utilizaron 
para ilustrar el Viaje del H.M.S. Beagle por América del Sur en esta conferencia.

El H.M.S. Beagle fue armado en Woolwich, Támesis, en 1820, y no participó en expedición alguna por varios años. En 1826 fue comandado por el Capitán Pringle Stokes en una travesía de exploración por América del Sur (1826-1830). Gran Bretaña tenía interés en encontrar rutas marítimas alternativas al paso por el Istmo de Panamá que tenía la corona Española. Por tal motivo realizó contactos con los recientemente emancipados países latinoamericanos para explorar las costas de Patagonia y Tierra del Fuego. La dificultad de la exploración tuvo un efecto depresivo en el Capitán Stokes, quien se quitó la vida en Patagonia en el año de 1829 . Como reemplazo y a la edad de 23 años, Robert FitzRoy (1805-1865) fue nombrado Capitán del Beagle.

En las costas de Tierra del Fuego en 1829-1830 se dan los motivos para la segunda expedición del H.M.S. Beagle, motivos un tanto ajenos a la expedición científica. Resulta que los habitantes de Tierra del Fuego robaron un bote y los miembros de la tripulación debieron improvisar su regreso al H.M.S. Beagle. Esta situación exasperó al Capitán FitzRoy, quien tomó como rehenes a tres patagones con la esperanza de negociar la devolución de su bote. Para su sorpresa, nadie reclamó a los rehenes. Entretanto la nave continuaba su travesía y Robert FitzRoy decidió mantener a los rehenes en el barco. Un cuarto habitante de Tierra del Fuego fue traído a bordo. El Capitán FitzRoy se preocupó de sus rehenes y los hizo vacunar en Río de Janeiro antes del regreso a Inglaterra en 1830.

La presencia de los patagones en Inglaterra no fue bien recibida por las autori- dades. Consciente de su responsabilidad, el Capitán FitzRoy decidió tomar un año de licencia, contratar un barco y devolver a su lugar de origen a los tres patagones. Pero el Capitán FitzRoy venía de una familia aristocrática, por lo que no fue necesario que pida la licencia. Al enterarse un pariente suyo de sus planes, utilizó su influencia para que el Almirantazgo Británico planifique una nueva expedición del H.M.S. Beagle para estudiar las costas de América del Sur, siendo Robert FitzRoy su Capitán.

Así, la casualidad del robo de un bote por parte de los patagones fue la causa incidental para la realización de una de las expediciones científicas más importantes (Keynes, 2002). El segundo viaje del H.M.S. Beagle se realizó entre 1831 a 1836. El mandato fue de cartografiar las costas del sur de América del Sur, incluyendo las Islas Malvinas y las Islas Galápagos y regresar dando la vuelta al mundo para medir las distancias a los meridianos de determinados lugares del globo.

Charles Darwin (1809-1882) acompañó como naturalista al H.M.S. Beagle en su segundo viaje. Era muy joven, pues tenía 22 años y no recibió salario u honorario alguno por su trabajo en el H.M.S. Beagle. $\mathrm{Su}$ vida a bordo fue muy difícil debido a que el movimiento del barco le causaba mareo y a las estrechas condiciones que brindaba la nave para la vida diaria y trabajo científico. En las costas de América del Sur encontró diferencias entre los animales que vivían en esas regiones y los numerosos fósiles que obtuvo en Argentina. Estas diferencias le llevaron a pensar que las especies no eran inmutables. La visita a las Islas Galápagos fortaleció estas ideas, pues en los animales de Galápagos encontró el 
sello de América del Sur, pero con variaciones. Sus colecciones durante el viaje del H.M.S. Beagle le sirvieron como materia prima para su teoría de la evolución de las especies.

El viaje del H.M.S. Beagle fue realizado por Charles Darwin, Robert FitzRoy y Conrad Martens que eran muy jóvenes, como lo son los estudiantes universitarios. A ellos va un mensaje de estímulo: como Charles Darwin realicen sus tareas con pasión para alcanzar las metas de su vida.

Agradecimiento a Richard Darwin Keynes y Simon Darwin Keynes por el apoyo brindado a esta presentación.

\section{BIBLIOGRAFÍA}

Keynes, R. (Ed.) (1979). The Beagle Record: Selections from the Original Pictorial Records and Written Accounts of the Voyage of the H.M.S. Beagle. Cambridge: Cambridge University Press.

Keynes, Richard. 2002. Fossils, Finches and Fuegians: Charles Darwin's Adventures and Discoveries on the Beagle, 1832-1836. London: Harper Collins Publishers.

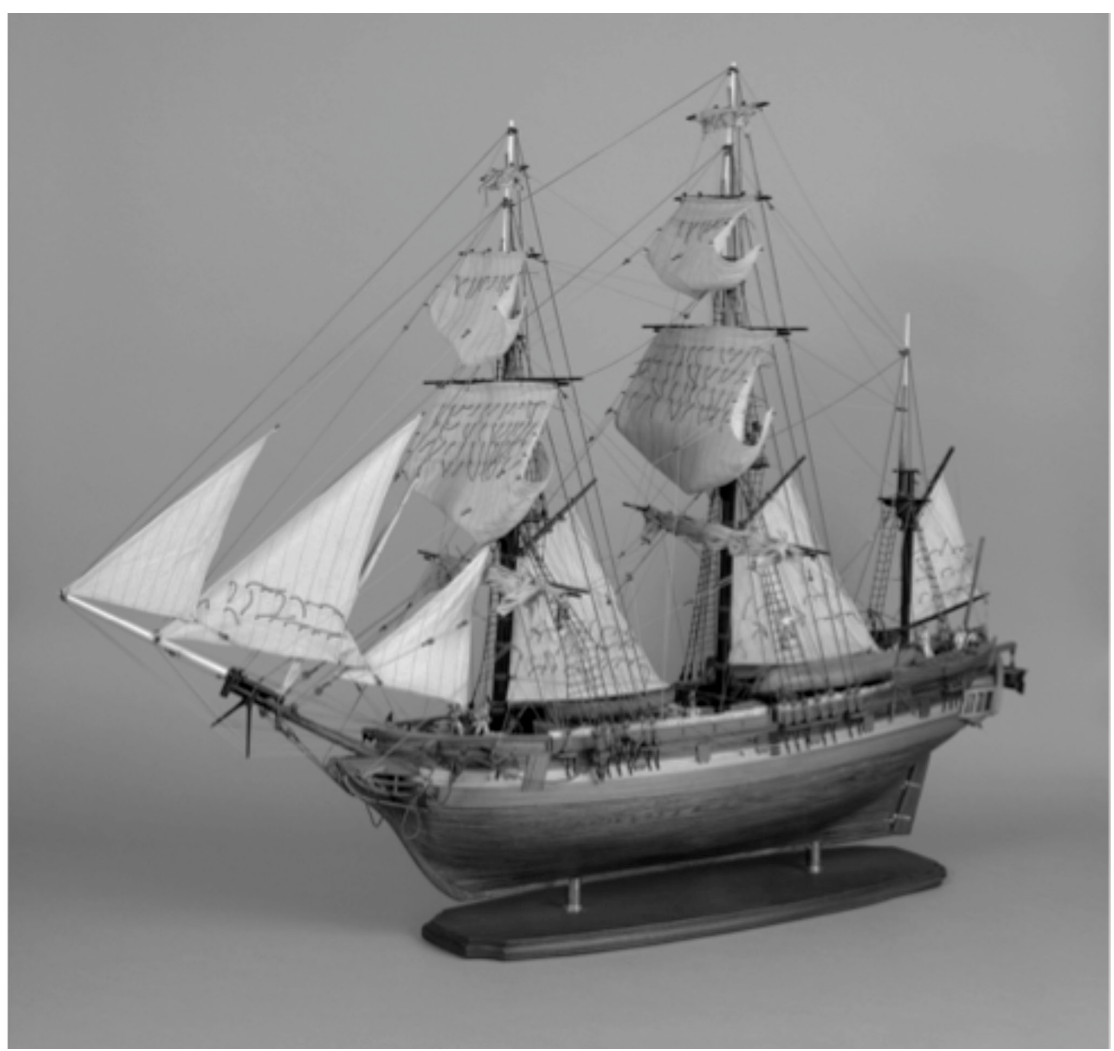

Figura 1. Modelo del H.M.S. Beagle fabricado a petición de Simon Darwin Keynes. Construido a escala 1:40 en 2006-2007 sobre la base del estudio de K.-H. Marquardt ("H.M.S: Beagle" Londres, 1997). Derechos de autor de la imagen: Prof. S. D. Keynes. 